\title{
Aqueous biological graphene based formulations for ink-jet printing
}

\author{
Łucja Dybowska-Sarapuk ${ }^{1,5}$, Sławomir Rumiński ${ }^{2,3,4}{ }^{4}$, Grzegorz Wróblewski ${ }^{1}$, Marcin Słoma ${ }^{1}$, \\ Anna Młożniak ${ }^{5}$, Ilona Kalaszczyńska ${ }^{2,3}$, Małgorzata Lewandowska-Szumieł ${ }^{2,3}$, \\ Małgorzata Jakubowska ${ }^{1,5}$
}

\author{
${ }^{1}$ Warsaw University of Technology, Faculty of Mechatronics, Andrzeja Boboli 8, 02-525 Warsaw, Poland, \\ ${ }^{2}$ Medical University of Warsaw, Department of Histology and Embryology, Centre for Biostructure Research, \\ Chatubińskiego 5, 02-004 Warsaw, Poland \\ ${ }^{3}$ Centre for Preclinical Research and Technology, Banacha 1B, 02-097 Warsaw, Poland \\ ${ }^{4}$ Postgraduate School of Molecular Medicine, Żwirki i Wigury 61, 02-091 Warsaw, Poland \\ ${ }^{5}$ Institute of Electronic Materials Technology, Wólczyńska 133, 01-919 Warsaw, Poland \\ Corresponding author: e-mail: l.dybowska@mchtr.pw.edu.pl
}

\begin{abstract}
The aim of the study was to produce heterophasic graphene nanoplatelets based formulation designed for ink-jet printing and biomedical applications. The compositions should meet two conditions: should be cytocompatible and have the rheological properties that allow to apply it with ink-jet printing technique. In view of the above conditions, the selection of suspensions components, such as binder, solvent and surfactants was performed. In the first stage of the research the homogeneity of the dispersion of nanoplatelets and their sedimentation behaviour in diverse solutions were tested. Subsequently, the cytotoxicity of each ink on human mesenchymal stem cells was examined using the Alamar Blue Test. At the same time the rheology of the resulting suspensions was tested. As a result of these tests the best ink composition was elaborated: water, polyethylene glycol, graphene nanoplatelets and the surfactant from DuPont company.
\end{abstract}

Keywords: ink-jet printing, graphene, mesenchymal stem cells, cytotoxicity.

\section{INTRODUCTION}

Graphene is a carbon nanomaterial which has attained an enormous popularity in the recent times. The material exhibits unique electronic, mechanical, thermal and optical properties and is distinguished by high surface area to volume ratio. Therefore it can be implemented in various applications in diverse fields of science, not only in electronics but also in materials technology, nanomedicine and tissue engineering ${ }^{1-5}$.

Adipose derived stem cells (ADSC) belong to the family of mesenchymal stem cells and have attracted great research interest in the past 15 years due to their potential application in regenerative medicine and tissue engineering. These cells can be isolated from an adult individual in large numbers by the use of minimally invasive liposuction procedure. The obtained ADSC are capable of differentiating into several specialized cell types, including osteoblasts, chondrocytes, adipocytes, myocytes, hepatocytes and pancreatic islets ${ }^{6}$. ADSC exert potent immunomodulatory effects ${ }^{7}$ and produce high amounts of growth factors, cytokines and chemokines ${ }^{8}$. All those features of ADSC make them particularly useful for tissue regeneration or replacement in a number of clinical disorders.

Transplantation of cells in a tissue engineering approach is usually performed together with a biomaterial, that forms a scaffold for cell attachment and tissue formation in the recipient's organism. The material that makes the scaffold might influence the biological properties of cells, including their proliferation, differentiation or growth factor production. Graphene is being explored as a candidate material for enrichment of cell scaffolds ${ }^{4,9,10}$, which could provide certain biological stimuli to increase the regenerative potential of ADSC. So far, several authors have studied the influence of graphene nanoparticles added into the culture medium on normal mammalian cells. In some of these studies graphene was found to be toxic at high concentrations $\mathbf{s}^{1,11,12}$, in others was described positive effect of graphene oxide on cell proliferation ${ }^{13}$. However, in our opinion from the tissue engineering point of view, it is more relevant to study the effect of graphene in direct contact with ADSC, i.e. when the cells are seeded onto a GNP-containing coating.

Using ink-jet printing technique, which is one of the most promising technologies, it is possible to obtain a particular pattern on various substrates ${ }^{14}$. Inkjet printing is used as the key technology in electronics (for organic transistors, solar cells, sensors) $)^{15}$, but it can be used successfully in tissue engineering to cell printing. Inkjet drop on demand method allows to print living cells in two or three dimensions in order to induce stem cell to preferentially differentiate into specific lineage ${ }^{\mathbf{1 0},{ }^{16} \text {. }}$

To make it possible, using materials - the biological inks should meet both engineering and biological requirements. First of all the ink cannot be toxic to the cells, thus biocompatibility of inks is a required characteristic. However, it is equally important that the ink is easily printable. Therefore, it must meet the rheological requirements such as suitable viscosity and surface tension and must exhibit good stability and particle dispersion ${ }^{14,16-18}$. According to Nelo et al. ${ }^{19}$ the stabilization of the particles in the suspension is actually the key of good ink formulation. All of above mentioned conditions can be achieved by selecting the correct ink composition.

Composite suspensions used for printing electronic components with ink-jet printing technique, called heterophasic inks, consist of two main materials: the functional phase and the binder. The functional phase influences the physical properties of the ink and determines the deposited layer functionality e.g. electrical conductivity. The binder plays the role of the matrix for the functional phase, and is responsible for the ink rheology and adhesion of printed layer to the substrate. Binders 
often used in electronics consist of diverse polymers and solvents such as ethylene glycol, terpineol, ethanol, deionized water, isopropyl alcohol, $\mathrm{N}$-metylpyrolidone, pluronic and others $\mathbf{1 , 1 4 , 2 0 , 2 1}$. For bio-inks hydrogels are used, comprising a biocompatible material include poly(acrylic acid) PAA, poly(ethylene glycol) and its copolymers, poly(vinyl acrylate) PVA and self-assembling polypeptides $^{22}$.

Surfactants are often added in inks used in electronics and medicine in order to obtain stable suspensions. The surfactants can improve the dispersion of the functional phase particles in the binder matrix and also improve the rheological properties, positively influencing the inkjet printing process and the formation of drops of specific sizes and shapes ${ }^{14,17,18}$.

The composition and properties of graphene formulations for ink-jet printing applied to biomedical applications, the effect of graphene platelets in direct contact with ADSC have not yet been investigated thoroughly. Therefore in this study, we aimed to prepare GNP-containing heterophasic suspensions suitable for ink-jet printing technology, that would be compatible with ADSC cells or biological molecules.

\section{METHODOLOGY}

\section{Material and instrumentation}

A wide variety of materials was tested as potential nontoxic components of the formulations suitable for ink-jet printing. Deionized water was used as a solvent. Consequently, selection of the organic binder was limited to water soluble materials. The list of the tested polymers is shown below in the Table 1. Two types of graphene nanoplatelets were subjected to tests as functional phase. They were GNP1 or GNP2 produced by direct exfoliation with the size of the platelets, in turn: about 15 or $8 \mu \mathrm{m}$ and platelets average thickness about $10 \mathrm{~nm}$.

Table 1. The list of used polymer materials
The viscosities of the prepared compositions were measured at $25^{\circ} \mathrm{C}$ using the BOOKFIELD DV2T cone plate rheometer. The temperature was set by the ultrathermostat Polyscience.

\section{Cell culture}

Adipose tissue was obtained from a healthy female donor undergoing cosmetic liposuction procedure, which would have been otherwise discarded. The tissue was processed to isolate adipose tissue derived mesenchymal stem cells (ADSC) according to standard, previously published method ${ }^{23}$, with minor modifications. Briefly, adipose tissue was washed three times in phosphate-buffered saline buffer (PBS) and agitated at $37^{\circ} \mathrm{C}$ for $1 \mathrm{~h}$ with equal volume of collagenase dissolved in Dullbeco Modified Eagle Medium (DMEM) with HEPES buffer (Gibco). The digested tissue was centrifuged at $400 \mathrm{x} \mathrm{g}$ and the cell pellet was suspended in complete culture medium (CCM) composed of DMEM supplemented with $10 \%$ FBS, $1 \%$ antibiotic-antymycotic (Gibco), $2 \mathrm{mM}$ L-glutamine (Gibco) and $5 \mathrm{ng} / \mathrm{ml}$ fibroblast growth factor (FGF-2) (Sigma Aldrich). After centrifugation and resuspending the pellet in CCM, the cell suspension was filtered through a $100 \mu \mathrm{m}$ filter. The cells were counted in a hemocytometer and seeded into T75 flasks at the density of 2-3 million cells per flask and cultured in humidified atmosphere at $37^{\circ} \mathrm{C}$ and $5 \% \mathrm{CO}_{2}$. The culture medium was replaced $24 \mathrm{~h}$ after seeding. The cells were passaged when the culture reached confluence and were used in experiments at passage 4.

\section{Alamar Blue test \\ Cell culture plates were first coated with GNP by di- spensing $25 \mu \mathrm{l}$ of ink into each well of a 96 well culture plate (Nunc). The plate was then placed into forced air oven set at $37^{\circ} \mathrm{C}$ to evaporate the solvent within two days. The plate was then washed two times with sterile PBS. ADSC cells were detached from culture flasks and}

\begin{tabular}{|l|l|l|l|l|}
\hline No & \multicolumn{1}{|c|}{ Material } & Molecular Weight & \multicolumn{1}{|c|}{ Abbreviation } & \multicolumn{1}{|c|}{ Company and other information } \\
\hline 1. & Polyetylene glycol & 400 & PEG400 & Fluka Analytical \\
\hline 2. & Polyetylene glycol & 1500 & PEG1500 & Loba-chemie Wien Fischamend \\
\hline 3. & Poly(vinylalcohol) & $31000-50000$ & PVA31 & Acros Organics, 87-89\% hydrolized \\
\hline 4. & Poly(vinylalkohol) & $85000-124000$ & PVA85 & Acros Organics, 95.5-96.5\% hydrolized \\
\hline 5. & Pluronic F-127 & 12500 & PLR & Sigma-Aldrich \\
\hline
\end{tabular}

To some suspensions, in order to improve a dispersion state of GNP the surfactants (1-5 wt $\%)$ were added. Surfactants most commonly used in electronic materials are: sodium dodecylsulfate, sodium dodecylbenzensulfonate, sodium deoxycholate, dimetyl sulfoxide, sodium lauryl sulphate, triton $\mathrm{X}$ and others. However, many of them are toxic. For our test Capstone FS-3100 (C) from DuPont was used, because previously made trial showed no toxicity of them and AKM-0531 (D) Malialim series surfactant from NOF corporation because it was successfully used in previous works to create graphene inks and it much improved dispersion of the suspension.

Preparation of formulations consisted of sonication of 500 or $100 \mu \mathrm{g} / \mathrm{ml} \mathrm{GNP}$ in deionized water and water soluble polymer (5 $\mathrm{wt} \%)$. Before sonication of some suspensions, GNP were mixed with the surfactants. seeded into the prepared plate at the density of $2.4 \mathrm{x}$ $10^{3}$ cells per well. The cells were cultured in CCM for 3 days in humidified atmosphere at $37^{\circ} \mathrm{C}$ and $5 \% \mathrm{CO}_{2}$. The cultures were observed under inverted microscope daily. On day 3 , the medium was aspirated and $200 \mu \mathrm{l}$ of 1:10 solution of Alamar Blue reagent (Life Technologies) in DMEM medium was added to each well. The cells were further cultured for 4 hours and the obtained supernatant was transferred into a black 96well plate (Nunc). Fluorescence intensity of the solution at 540/10 $\mathrm{nm}$ excitation and 620/10 $\mathrm{nm}$ emission was measured in FluorStar plate reader (BMG Labtech). Alamar Blue solution incubated without cells was used as blank and the signal was normalized to ADSC cells cultured in uncoated standard culture plate. 


\section{RESULTS AND DISCUSSION}

The dispersion state and sedimentation of the inks functional phase particles

In this part of the experiment prepared formulations were subjected to observation, based on the level of dispersion of GNP in the suspension and the start time of functional phase sedimentation were determined. Collected conclusions were shown in the Table 2.

Among the different polymers used in this study, PLR is the only one that possesses hydrophobic moieties thus can improve the suspension quality by interacting with GNP $^{24}$. The conducted study confirmed that the PLR, as most hydrophosic was the most promising of polymers which result in good dispersion of GNP solution. The next was high molecular weight PEG 1500. In these media

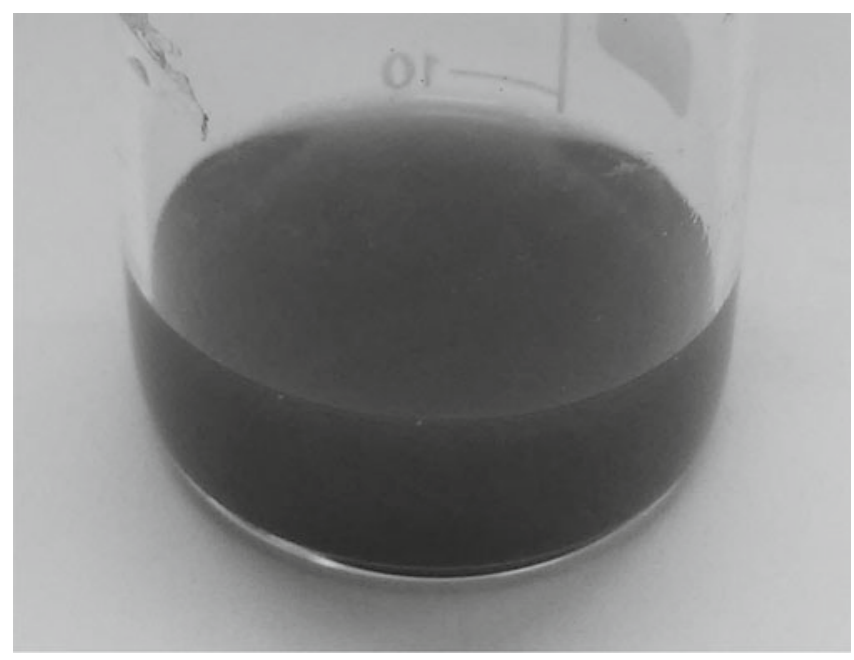

Figure 1. PEG1500 ink

Table 2. Prepared inks and conclusions from their observations

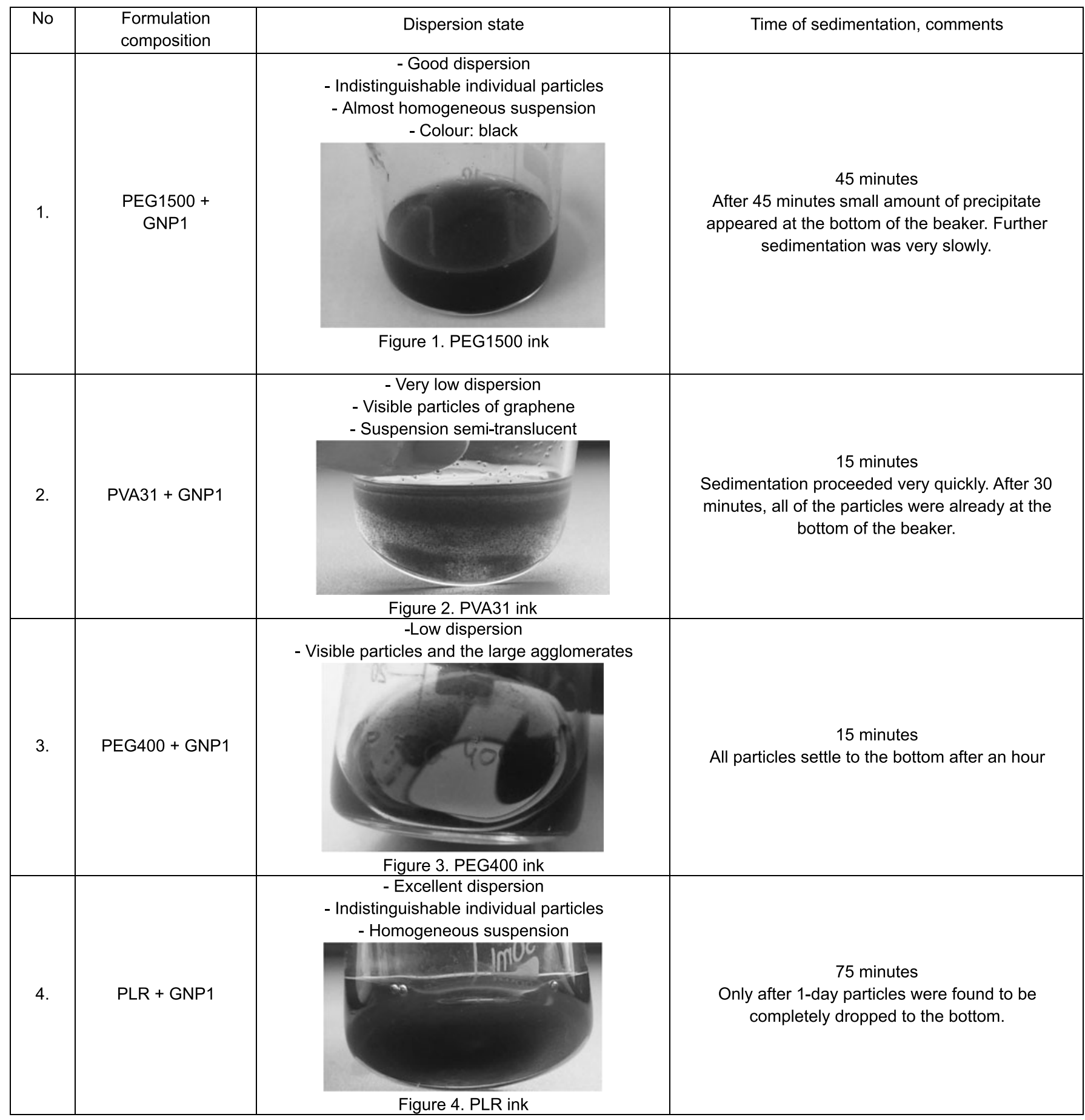




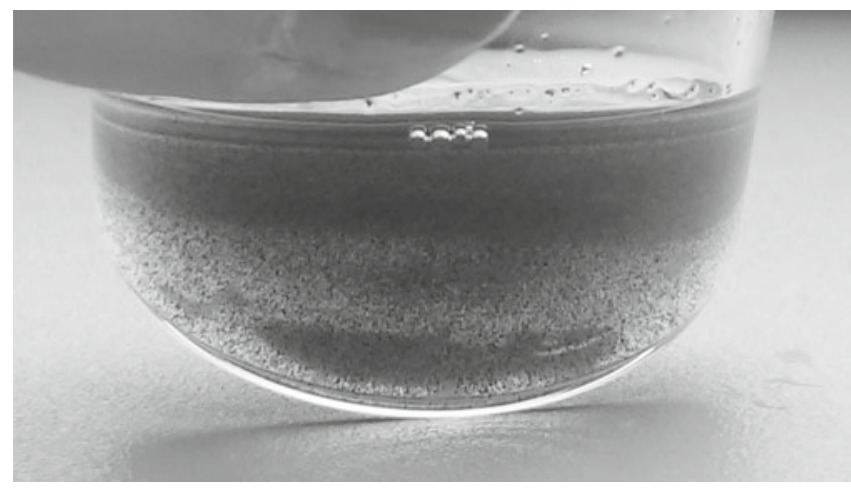

Figure 2. PVA31 ink

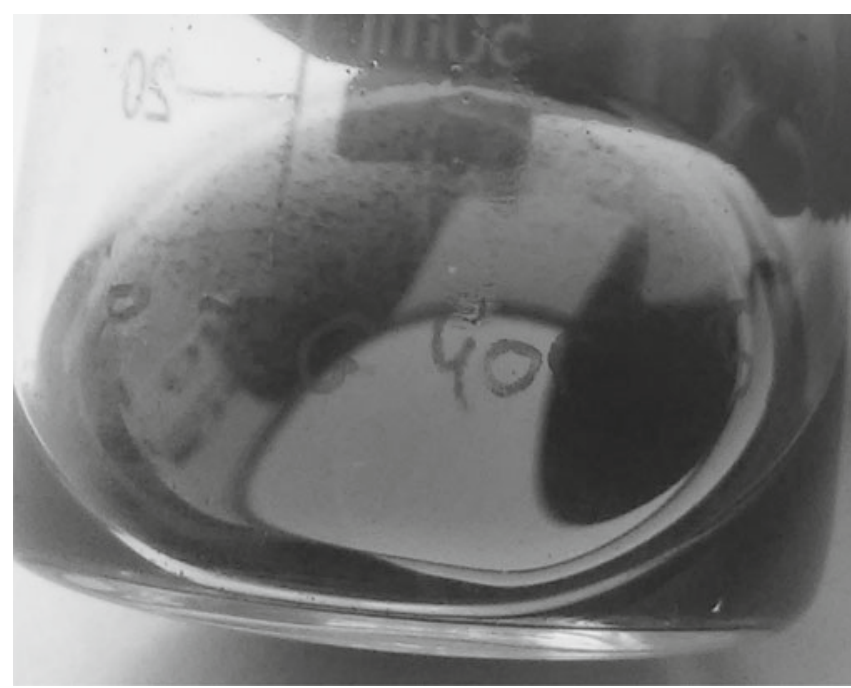

Figure 3. PEG400 ink

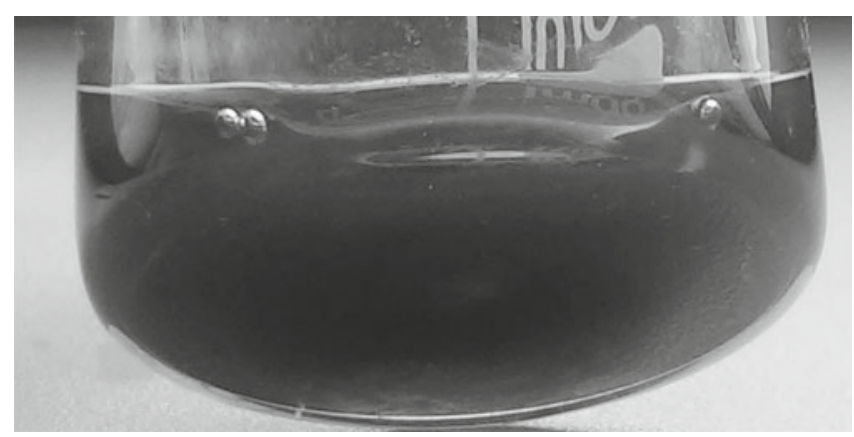

Figure 4. PLR ink

could be achieved not only good dispersion of the GNP but also the longest time stability of the suspension.

Both PVA and PEG 400 did not yield satisfactory results as organic vehicles of heterogeneous inks. Perhaps a better dispersion of particles could be obtained by increasing the content of these polymers in suspension. However, in case of biological inks, concentration of the vehicle should be kept low to avoid any cytotoxic effects and to minimize unspecific biological effects on studied cells. Based on the observations it was noted that molecular weight of the polymer influences on the properties of the ink. This may be due to change of viscosity of the suspension depending on the molecular weight of the polymer. Furthermore, low molecular weight PEG can exert cytotoxic effect in cell culture, while high molecular weight PEGs as regarded as biocompatible ${ }^{25}$. Therefore due to good performance as a vehicle for graphene nanoparticles and likely biological compatibility, only PEG1500 and PLR were used in subsequent experiments.

In the next step of the study the formulations were prepared on both the selected binder (PLR and PEG1500) using smaller sized graphene platelets (GNP2). Functional phase change was taken from two key reasons: we suppose that smaller GNP platelets can sediment less which increases the stability of the ink and that the ink will be easier printable without clogging the nozzle.

Since the addition of the surfactant is necessary to ensure correct formation of drops in the ink-jet inks, to some suspensions dispersants were also added. The conclusions from the observation of newly produced composition are shown in the table below.

The tests allowed to state that both the functional phase change and the addition of surfactant had a positive impact on particle sedimentation time and the state of dispersion solutions. The reason can be that the flakes of a smaller size, coated with an additional layer due to the use of surfactants, can more easily spread in the suspension.

For further research on rheology and cytocompatibility GNP2, both: PEG1500 and PLR and the two surfactants: $\mathrm{C}$ and $\mathrm{D}$ were used.

\section{Inks viscosity investigation}

In order to verify the suitability of selected (no. 6, 7, $9,10)$ inks for ink-jet technique, the inks viscosity was measured. The obtained viscosity curves were shown below in Figure 5.

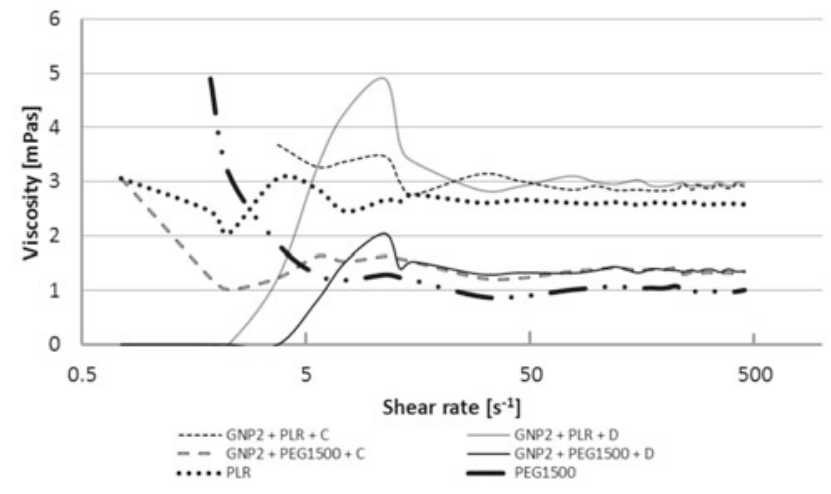

Figure 5. The viscosity curves of selected inks

Table 3. The inks with GNP2 and conclusions from theirs observations

\begin{tabular}{|c|l|l|}
\hline No & \multicolumn{1}{|c|}{ Ink composition } & \multicolumn{1}{c|}{ Conclusions from inks observations } \\
\hline 5. & PLR+GNP2 & $\begin{array}{l}\text { After } 85 \text { minutes, the first signs of sedimentation were observed. The level of } \\
\text { dispersion was high. }\end{array}$ \\
\hline 6. & PLR+GNP2+C & The level of dispersion has increased very slightly. \\
\hline 7. & PLR+GNP2+D & $\begin{array}{l}\text { The sedimentation was observed after } 55 \text { minutes. The level of particle dispersion was } \\
\text { the same as in the ink 5. }\end{array}$ \\
\hline 8. & PEG1500+GNP2 & The level of dispersion has increased very slightly. \\
\hline 9. & PEG1500+GNP2+C & Then \\
\hline 10. & PEG1500+GNP2+D &
\end{tabular}


The graph shows that viscosity curves of formulations, which contain the same binder, regardless of the type of added surfactant, are almost identical. It can be concluded that the type of polymer material used in the ink has the most influence on the viscosity.

In both cases, the viscosity of the carrier is smaller than that of the suspension containing graphene. We can also see that PEG1500 has nearly two times lower viscosity than the PLR. Therfore both inks containing PEG1500 had the viscosity value in the entire range of shear rates more than two times lower than inks in which the organic vehicle was PLR.

As can be seen on the graph, the viscosity of GNP2 + PLR + D formulation increases first at shear rate around $5 \mathrm{~s}^{-1}$, while the GNP2+PLR $+\mathrm{C}$ decreases. This is clearly caused by the difference of surfactants in inks. However, this is of no significance to the process of inkjet printing. As reported in Kyoohee et al. ${ }^{26}$, shear rates during ink-jet printing is on the order of $10^{5} 1 / \mathrm{s}$. In the case of tested formulations the viscosity values at the end of the measurement range of the viscometer are stabilized, the viscosity values for one of the last measured point were used.

For a shear rate of $450 \mathrm{~s}^{-1}$ viscosity of suspension with PEG1500 was about $1.36 \mathrm{mPas}$, and second ink $2.97 \mathrm{mPas}$. Petri et al. ${ }^{27}$ reported that for the ink-jet printing layer process it is proper (there is no satellite or double droplet) when viscosity is in the range from 1 to $20 \mathrm{mPas}$. It can be concluded that the viscosity of the two inks are within the range proposed for ink-jet printing inks so that it is possible to print them using this technique.

\section{Test Alamar Blue}

The results of Alamar Blue test indicated that Pluronic is not suitable as a bio-ink vehicle for GNPs. The normalized viability of ADSC cells was below $10 \%$ even when the lower concentration was used. Microscopic phase contrast images indicated that there were no adherent cells present in ink-coated culture wells starting from day 1 , which did not change until day 3 . In the coating with $100 \mu \mathrm{g} / \mathrm{ml}$ GNP concentration, circular,

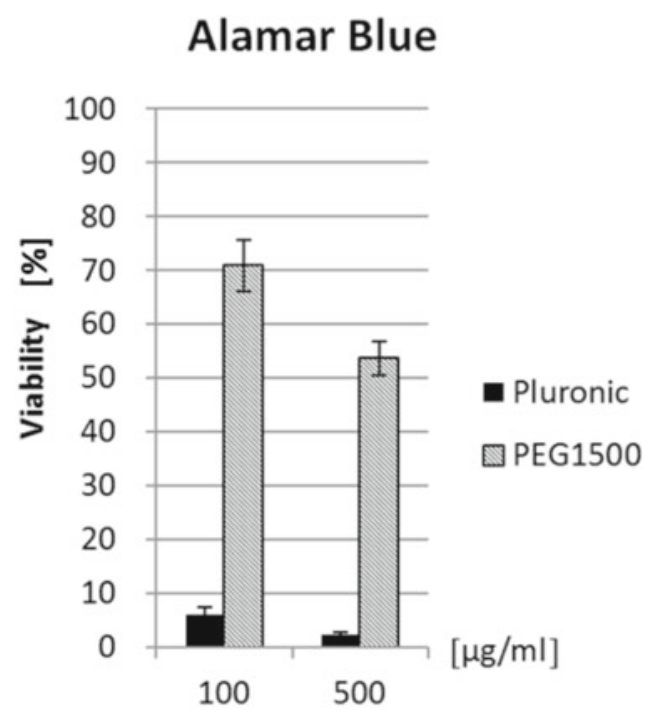

Figure 6. Cytotoxicity of GNP containing inks. Alamar Blue test performed on ADSC cells after 3 days of culture
$100 \mu \mathrm{g} / \mathrm{ml} \mathrm{GNP2}$
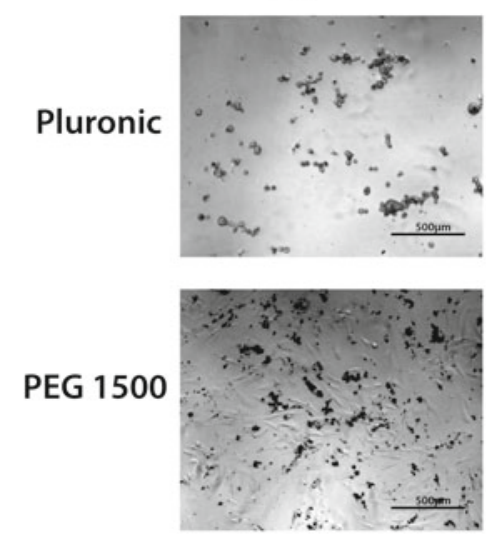

$500 \mu \mathrm{g} / \mathrm{ml} \mathrm{GNP2}$
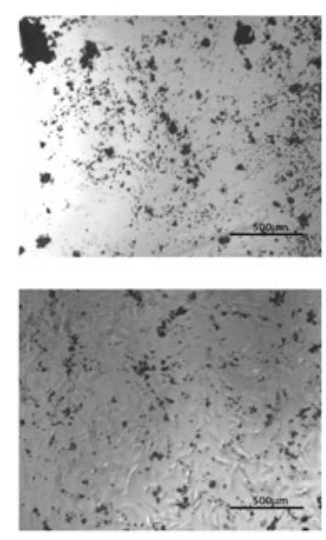

Figure 7. Cytotoxicity of GNP containing inks. Phase contrast images of representative cultures after 3 days of culture

non-adherent cells were present, which suggests that Pluronic prevents attachment of ADSC to the culture surface and therefore precludes cell proliferation. On the contrary, relative viability of ADSC on GNP inks containing PEG1500 as the vehicle was higher. Low concentration of PEG1500 resulted in 70\% viability relative to standard ADSC culture, while in the higher concentration of PEG1500, the average viability dropped to $54 \%$. Furthermore, ADSC cells attached to the coated surface and presented normal, spindle-shaped morphology. Despite having a negative effect on ADSC viable cell number compared to standard culture, PEG1500-based inks can be considered as a GNP vehicle because the prepared coatings allowed for cell attachment. The observed cytotoxic effect was most likely caused by GNP, as increasing GNP concentration decreased cell viability.

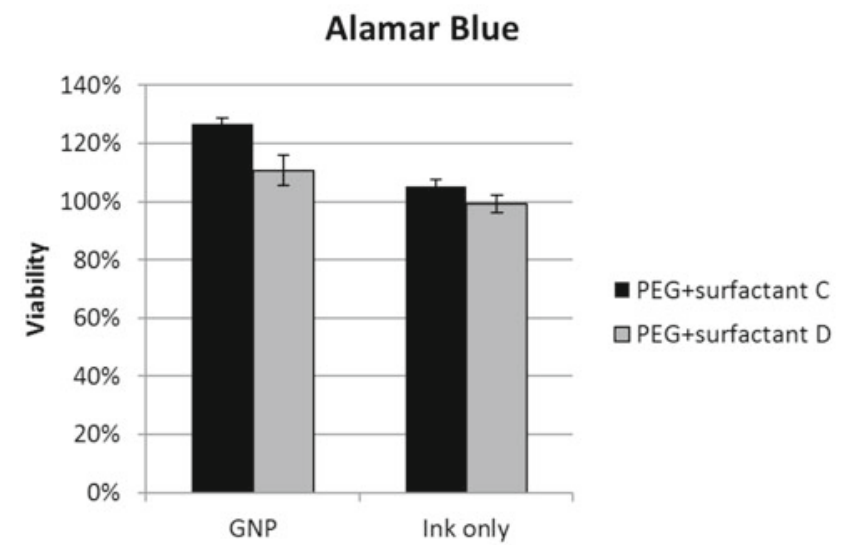

Figure 8. Cytotoxicity of GNP coatings prepared with the use of surfactants

Next, cytocompatibility of suspensions containing surfactants was assessed with the use of Alamar Blue test. The cell culture plate was coated with inks containing $500 \mu \mathrm{g} / \mathrm{ml} \mathrm{GNP}$, the higher of two concentrations tested in previous experiment. ADSC cells cultured on the prepared coatings showed increased relative viability. Addition of $2 \mathrm{wt} \%$ surfactants $\mathrm{C}$ and $\mathrm{D}$ resulted in viabilities above $100 \%$ of the control culture, with capstone giving slightly higher viability than " $D$ ". The coating prepared without the functional phase (ink only) resulted in viability of approximately $100 \%$, which indicates that the ink formulation, containing PEG1500 and 
either of the two surfactants is cytocompatibile. Therefore interestingly, presence of GNP particles in the inks slightly increases ADSC viability. The improved results in Alamar Blue test upon application of surfactants might potentially stem from better dispersion of GNP particles and consequently, diminished toxic effects. What is the mechanism of the beneficial effect of GNP on ADSC proliferation remains to be determined.

\section{CONCLUSION}

The aim of the study was to find the suitable composition of GNP water-based ink for biomedical applications for ink-jet printing technique. After the observations regarding the dispersion state and sedimentation rate of functional phase in elaborated inks, PLURONIC and PEG1500 were determined as the best polymers for the organic vehicle. Unfortunately PLURONIC was unsuitable as a vehicle for biological GNP inks due to lack of cell adhesion to the deposited coating. Rheological measurements have shown that there is no significant difference in the viscosity of the inks in relation to the type of the surfactant added to the same binder, therefore all elaborated inks were suitable for ink-jet printing technique. The surfactants added to the GNP inks were completely cytocompatible, with even slightly improved proliferation/viability over standard control cultures. Finally a new bio-ink formulation, exhibiting satisfying durability and rheological properties was established. This composition was as follows: solvent - the deionized water, binder - polyetylene glycol with the molecular weight 1500 and the commercial surfactant capstone FS-3100.

\section{LITERATURE CITED}

1. Wojtoniszak, M., Chen, X., Kalenczuk, R.J., Wajda, A., Łapczuk, J., Kurzewski, M., Drozdzik, M., Chu, P.K. \& Borowiak-Palen, E. (2012). Synthesis, dispersion, and cytocompatibility of graphene oxide and reduced graphene oxide. Colloids and Surfaces B: Biointerfaces 89, 79-85. DOI: 10.1016/j. colsurfb.2011.08.026.

2. Huang, L., Huang, Y., Liang, J., Wan, X. \& Chen, Y. (2011). Graphene-Based Conducting Inks for Direct Inkjet Printing of Flexible Conductive Patterns and Their Applications in Electric Circuits and Chemical Sensors. Nano Res. 4(7), 675-684. DOI: 10.1007/s12274-011-0123-z.

3. Jangho, K., Kyoung, S.C., Yeonju, K., Ki-Tack, L., Hoon, S., Yensil, P., Deok-Ho, K., Pill-Hoon, C., Chong-Su, C., Soo, Y.K., Yun-Hoon, C. \& Jong, H.C. (2013). Bioactive effects of graphene oxide cell culture substratum on structure and function of human adipose-derived stem cells. J. Biomed. Mater. Res. Part A. 101(12), 3520-3530. DOI: 10.1002/jbm.a.34659.

4. Carrow, J.K. \& Gaharwar, A.K. (2015). Bioinspired Polymeric Nanocomposites for Regenerative Medicine. Macromol. Chem. Phys. 216(3), 248-264. DOI: 10.1002/macp.201400427.

5. Xu, Y., Liu, Z., Zhang, X., Wang, Y., Tian, J., Huang, Y., Ma, Y., Zhang, X. \& Chen, Y. (2009). A Graphene Hybrid Material Covalently Functionalized with Porphyrin: Synthesis and Optical Limiting Property. Adv. Mater. 21(12), 1275-1279. DOI: 10.1002/adma.200801617.

6. Huang, S.J., et al. (2013). Adipose-derived stem cells: isolation, characterization, and differentiation potential. Cell Transplant 22(4), 701-9. DOI: 10.3727/096368912X655127.

7. Yi, T. \& Song, S.U. (2012). Immunomodulatory properties of mesenchymal stem cells and their therapeutic applications.
Arch. Pharm. Res. 35(2), 213-221. DOI: 10.1007/s12272-0120202-z.

8. Kapur, S.K. \& Katz, A.J. (2013). Review of the adipose derived stem cell secretome. Biochimie 95(12), 2222-2228. DOI: 10.1016/j.biochi.2013.06.001.

9. Zhanga, Y., Nayakb, T.R., Hongb, H. \& Caia, W. (2012) Graphene: a versatile nanoplatform for biomedical applications. Nanoscale 4, 3833-3842. DOI: 10.1039/C2NR31040F.

10. Li, N., Zhang, Q., Gao, S., Song, Q., Huang, R., Wang, L., Liu, L., Dai, J., Tang, M. \& Cheng, G. (2013). Three-dimensional graphene foam as a biocompatible and conductive scaffold for neural stem cells. Sci. Rep. 3, 1604, DOI: 10.1038/ srep01604.

11. Sanchez, V.C., Jachak, A., Hurt, R.H. \& Kane, A.B. (2012). Biological Interactions of Graphene-Family Nanomaterials - An Interdisciplinary Review. Chem. Res. Toxicol 25(1), 15-34. DOI: 10.1021/tx200339h.

12. Akhavan, O., Ghaderi, E. \& Akhavan, A. (2012). Size-dependent genotoxicity of graphene nanoplatelets in human stem cells. Biomaterials 33(32). DOI: 10.1016/j.biomaterials.2012.07.040.

13. Kim, T.H., Shah, S., Yang, L., Yin, P.T., Hossain, M.K., Conley, B., Choi, J.W. \& Lee, K.B. (2015) Controlling Differentiation of Adipose-Derived Stem Cells Using Combinatorial Graphene Hybrid-Pattern Arrays. ACS Nano 9(4), 3780-3790. DOI: 10.1021/nn5066028.

14. Woo, K., Jang, D. Kim, Y. \& Moonn, J. (2013). Relationship between printability and rheological behavior of ink-jet conductive inks. Ceramics Inter. 39(6), 7015-7021. DOI: 10.1016/j.ceramint.2013.02.039.

15. Xu, Y. Hennig, I., Freyberg, D., Strudwick, A.J., Schwab, M.G., Weitz, T. \& Cha, K.C. (2014). Inkjet-printed energy storage device using graphene/polyaniline inks. J. Power Sour. 248, 483-488. DOI: 10.1016/j.jpowsour.2013.09.096.

16. Ferris, C. (2013). Bio-inks for drop-on-demand cell printing, University of Wollongong, from research online on the World Wide Web: http://ro.uow.edu.au/theses/3875/

17. Gamota, D., Brazis, P., Kalyanasundaram, K. \& Zhang, J. (2004). Printed Organic and Molecular Electronics. Springer Science+Business Media, LLC, from SpringerLink.

18. Kamyshny, A., Steinke, J. \& Magdassi S. (2011). Metalbased Inkjet Inks for Printed Electronics, The Open Appl. Phys. J. 4, 19-36. DOI: 1874-1835/11.

19. Nelo, M., Sowpati, A.K., Palukuru, V.K., Juuti, J. \& Jantunen, H. (2010). Formulation of Screen Printable Cobalt Nanoparticle Ink for High Frequency Applications. Prog. Electromag. Res. 110. DOI: 10.2528/PIER10102101.

20. Li, J., Ye, F., Vaziri, S., Muhammed, M., Lemme, M.C. \& Östling, M. (2013). Efficient Inkjet Printing of Graphene. Adv. Mater. 25(29), 3985-3992. DOI: 0.1002/adma.201300361.

21. Torrisi, F., Hasan, T., Wu, W., Sun, Z., Lombardo, A., Kulmala, T.S., Hsieh, G.W., Jung, S., Bonaccorso, F., Paul, P.J., Chu, D. \& Ferrari, A.C. (2012). Inkjet printed graphene electronics. ACS Nano 6(4), 2992-3006, DOI: 10.1021/nn2044609.

22. Ferris, C. (2013), Bio-inks for drop-on-demand cell printing, University of Wollongong.

23. Zuk, P.A., et al. (2001). Multilineage cells from human adipose tissue: implications for cell-based therapies. Tissue Eng. 7(2), 211-228. DOI: 10.1089/107632701300062859.

24 Sheng-Zhen, Z. \& Bao-Hang, H. (2009). Aqueous Dispersion of Graphene Sheets Stabilized by Pluronic Copolymers: Formation of Supramolecular Hydrogel J. Phys. Chem. C. 113(31), 13651-13657. DOI: 10.1021/jp9035887.

25. Biondi, O., Motta, S. \& Mosesso, P. (2002). Low molecular weight polyethylene glycol induces chromosome aberrations in Chinese hamster cells cultured in vitro. Mutagenesis 17(3), 261-264. DOI: 10.1093/mutage/17.3.261.

26. Kyoohee, W., Daehwan, J., Youngwoo, K. \& Jooho, M. Relationship between printability and rheological behavior 
of ink-jet conductive inks. Ceramics Inter. (2013), Vol. 39, 7015-7021. DOI: 10.1016/j.ceramint.2013.02.039.

27. Ihalainen, P., Määttänen, A. \& Sandler, N. (2015). Printing technologies for biomolecule and cell-based applications. Inter.

J. Pharmac. DOI: 10.1016/j.ijpharm.2015.02.033. 